\title{
Advanced Solid State Nano-electrochemical Sensors and System for Agri 4.0 Applications
}

\author{
Ian Seymour 1, Tarun Narayan ${ }^{1,}$ Niamh Creedon ${ }^{1}$, Kathleen Kennedy ${ }^{1}$, Aidan Murphy ${ }^{2}$, Riona \\ Sayers 3, Emer Kennedy ${ }^{3}$, Ivan O'Connell ${ }^{2}$, James Rohan ${ }^{4}$, Alan O’Riordan 1* \\ ${ }^{1}$ Nanotechnology Group, Tyndall National Institute, Cork, Ireland; alan.oriordan@tyndall.ie \\ ${ }_{2}^{2}$ Microelectronics Circuit Centre Ireland, Tyndall National Institute, Cork, Ireland; ivan.oconnell@mcci.ie \\ ${ }^{3}$ Teagasc Food Research Centre Moorepark, Fermoy, Cork, Ireland; emer.kennedy@teagasc.ie \\ ${ }^{4}$ Electrochemical Materials and Energy Group, Tyndall National Institute, Cork, Ireland; \\ james.rohan@tyndall.ie \\ * Correspondence: alan.oriordan@tyndall.ie
}

Received: date; Accepted: date; Published: date

Abstract: Global food production needs to increase in order to meet the demands of an ever growing population. As resources are finite, the most feasible way to meet this demand is to minimize losses and improving efficiency. Regular monitoring of factors like animal health, soil and water quality for example, can ensure that the resources are being used to their maximum efficiency. Existing monitoring techniques however have limitations, such as portability, turnaround time and requirement for additional reagents. In this work, we explore the use of micro and nano scale electrode devices, for the development of electrochemical sensing platform to digitalize a wide range of applications within the Agri-food sector. With this platform, we demonstrate the direct electrochemical detection of pesticides, specifically clothianidin and imidacloprid with detection limits of $0.22 \mathrm{ng} / \mathrm{mL}$ and $2.14 \mathrm{ng} / \mathrm{mL}$ respectively, and nitrates with a detection limit of $0.2 \mu \mathrm{M}$. In addition, interdigitated electrode structures also enable an in-situ $\mathrm{pH}$ control technique to mitigate $\mathrm{pH}$ as an interference and modify analyte response. This technique is applied to the analysis of monochloramine, a common water disinfectant. Concerning biosensing, the sensors are modified with biomolecular probes for the detection of both bovine viral diarrhea virus particles and antibodies, over a range of $1 \mathrm{ng} / \mathrm{mL}$ to $10 \mu \mathrm{g} / \mathrm{mL}$. Finally, a portable analogue front end electronic reader is developed to allow portable sensing, with control and readout undertaken using a smart phone application. Finally, the sensor chip platform is integrated with these electronics to provide a fully functional end-to-end smart sensor system compatible with emerging AgriFood digital decision support tools.

Keywords: Electrochemical Sensors; Agriculture; Nanosensors; Biosensors; Nitrates; Pesticides; pH Control; Virus Detection

\section{Introduction}

With the global population continuing to expand, there is now an urgent need to produce more food, up to $70 \%$ by 2050 , more efficiently with the available existing finite resources.[1] This is a key societal challenge that is a call to action for global political leaders. To this end, the World Government Summit published, in 2018, their report called "Agriculture 4.0 - The Future of Farming Technology", which addressed the four main developments they identified as placing pressure on agriculture: Demographics, Scarcity of natural resources, Climate change, and Food waste.[2] Similarly, in 2019, the European set forth its European Green Deal for the European Union (EU) and its citizens. This is "a new growth strategy that aims to transform the EU into a fair and prosperous 
society, with a modern, resource-efficient and competitive economy where there are no net emissions of greenhouse gases in 2050 and where economic growth is decoupled from resource use".[3] Producers and processers on the front line are key to managing the transition to more sustainable systems of food production to reduce air, water and soil pollution, biodiversity loss and climate change, and excessive consumption of natural resources. New digital technologies are therefore required, at all stages of production, to enhance food security, reduce losses, increase sustainable production (through precision agriculture), increase economic return while also protecting biodiversity. Agriculture 4.0 is the term for this challenge facing the Agri-food industry, and will necessarily include a greater focus on, the use of the internet of things (IoT) and big data to drive greater business efficiencies.

Digital technologies have the potential to revolutionize the whole Agri-food and the environment supply chain and will play a great role in transforming the traditional based agriculture industry to a knowledge based one. The increased connectivity of a global agriculture would enable producers to use their data to apply the 4R farm management strategy Right product, Right place, Right time, Right rate, while processors can employ data to reduces losses, maximize production, increase quality and address consumer concerns, e.g., traceability. To enable this paradigm shift, new decision support tools and advanced analytics based on embedded and connected point-of-use sensors and systems are required to yield (quasi)real time data that will provide informed decision making capacity to stakeholders. Given the huge diversity in potential uses-cases, for example, plant and animal health monitoring, [4-6] to pesticide and antibiotics residue detection, [7-9] through to soil and water quality measurements[10-13] a suite of new connected sensor systems that are fit for purpose are proposed. To date a number of sensors based on optical,[14-16] chemical,[17, 18] electromechanical detection mechanisms[19, 20] have been developed, by a number of research groups, but can be limited in terms of portability, deployment incompatibilities and cost.

By contrast, electrochemical sensors have a number of adventitious properties that make them particularly suitable for point-of-use applications. They are highly sensitive and portable, are relatively low cost, exhibit a rapid time-to-result, are highly versatile e.g., different, electrode materials $(\mathrm{C}, \mathrm{Au}, \mathrm{Pt})$ are suitable for a variety of different chemical molecules, and may also be modified with a large variety of biomolecules for bio-sensing applications.[21-24] Furthermore, they are low power and provide an electrical transduction signal; which may be fed directly into electronic systems (without conversion) amplified, undergo edge analytics with the resultant data sent to the cloud.[25] Further advantages may be accrued when nanoscale or ultra-microelectrodes (typically smaller than the diffusion zone) are employed as the sensing element. These include: greater sensitivity arising from enhanced analyte mass transport due to radial diffusion profiles, faster analysis, lower solution resistance reducing/eliminating the need for background electrolyte and greatly reduced capacitive charging.[26-28] Consequently, electrochemical nanosensors have tremendous potential for use in sustainable Agri-Food and environmental point-of-use deployment applications.

In recent years, advances in fabrication techniques have enabled the development of solid-state micro/nano electrochemical sensor devices.[27, 29-31] Using these fabrication approaches, we are developing a highly versatile silicon chip-based electrochemical sensor platform that incorporates multiple sensing electrodes, on-chip counter and reference electrodes, with electrical connection of the sensors to custom electronics facilitated through edge connectors based on SD card pinouts. This sensor platform is highly versatile, may be easily integrated with analogue front end electronics and can address a number of sensing challenges described above. Consequently, in this paper we present for the first time: (i) highly sensitive detection of neonicotinoid insecticides ( 1 part per billion) in water using gold nanowire arrays, (ii) copper modified sensors for selective nitrate detection $(1-100$ $\mu \mathrm{mol} / \mathrm{L}$ ), (iii) bio-modified sensors for Bovine Viral Diarrhoea disease detection (both viruses and antibodies), (vi) we demonstrate generator-collector electrochemical approaches for both $\mathrm{pH}$ 
measurements and in-situ pH control, required for remote analysis. Finally, (v) we integrate these sensor devices with bespoke electronics controlled using a custom written app on a Smart phone and thus demonstrate an end-to-end sensor system.

\section{Materials and Methods}

\subsection{Nanowire fabrication:}

Silicon chip based devices were fabricated using methods similar to those described by Dawson et al.[32, 33] Chips were designed to interface with external electronics via a microSD port to facilitate facile electrical connection. Gold nanowire array electrodes are fabricated using a hybrid electron beam / photolithography process on a four-inch wafer silicon substrates bearing a $300 \mathrm{~nm}$ layer of thermally grown silicon dioxide. Blanket metal evaporations of Titanium $(10 \mathrm{~nm})$ and Gold $(100 \mathrm{~nm})$ using a Temescal FC-2000 E-beam evaporator and lift-off technique yields single, and arrays of nanowires. A second metal evaporation and lift-off process yields the interconnection tracks, contact pads and the gold counter electrode $(90 \mu \mathrm{m} \times 7 \mathrm{~mm})$. Finally, a third metal evaporation was performed to create the platinum pseudo reference electrode. To prevent unwanted interactions along the connection tracks, silicon nitride, which acts as an insulating layer was deposited by plasma, enhanced chemical vapour deposition. Photolithography and dry etching were utilised to selectively open windows $(45 \mu \mathrm{m} \times 100 \mu \mathrm{m})$ in the insulating SiN layer over the microband electrodes for exposure to the electrolyte. Openings were also created over the counter and pseudo-reference electrodes and the contact pads. Each device contains six interdigitated electrode (sensors) which are separated by $0.94 \mathrm{~mm}$. Once the sensor fabrication is completed, a wafer was diced into 28 separate chip devices.

\subsection{Ultramicro Electrode Array Fabrication}

Single microbands and interdigitated arrays were fabricated as in the previous section, with the initial lithography step being photolithography rather than e-beam lithography. Each chip consisted of two combs of gold working interdigitated electrodes ( $55 \mu \mathrm{m} \times 1 \mu \mathrm{m} \times 60 \mathrm{~nm}$ ), platinum pseudo reference and gold counter electrode. The interdigitated structures had gaps between the combs of 2 $\mu \mathrm{m}$.

\subsection{Optical Characterisation}

Optical micrographs were acquired using a calibrated microscope (Axioskop II, Carl Zeiss Ltd.) equipped with a charge-coupled detector camera (CCD; DEI-750, Optronics). Scanning electron microscopy analysis was undertaken to characterize the substrate surface after the fabrication procedure. SEM images were acquired using a calibrated field emission SEM (JSM-7500F, JEOL UK Ltd.) operating at beam voltages between 3 and $5 \mathrm{kV}$.

\subsection{Electrochemical Characterisation for Nanowire Arrays}

All electrochemical experiments were performed using Autolab Bipotentiostat (MAC80150) and a Faraday Cage connected to a PC. A three electrode electrochemical system was implemented; using a single microband ( $1 \mu \mathrm{m}$ wide, $45 \mu \mathrm{m}$ long) or an array of 4 gold nanowires (100 nm wide, $45 \mu \mathrm{m}$ long separation $500 \mathrm{~nm}$ ) as the working electrodes versus the on-chip platinum pseudo-reference and gold counter electrodes. The cell incorporates a custom chip holder and microSD edge connector to permit electrical contact to the working electrodes, and a sample well for the electrolyte solution. Prior to all electrochemical measurements, electrodes were cleaned using a mixed solvent clean process (acetone, isopropyl alcohol and DI water) for 15 minutes and dried under a stream of nitrogen. To confirm electrode functionality cyclic voltammetry $(\mathrm{CV})$ experiments were first undertaken in a $1 \mathrm{mM}$ Ferrocenemonocarboxylic acid (FCA, Sigma Aldrich) solution in $10 \mathrm{mM}$ 
phosphate buffer saline solution (PBS, pH 7.4, Sigma Aldrich). CV measurements were carried out in the potential range -0.2 to $0.6 \mathrm{~V}$ at a scan rate of $100 \mathrm{mVs}-1$.

\subsection{Electrochemical Characterisation for Interdigitated Arrays}

Each chip was inspected using optical microscopy to identify any obvious defects or faults. Prior to any electrochemical characterisation, chips were cleaned by immersion in acetone, then iso-propyl alcohol and finally de-ionized water, each for a period of ten minutes. The chips were dried in a flow of nitrogen and placed in the chip holder. Electrochemical analysis was performed using a with BA Module, Metrohm). Cyclic voltammograms (CV) were performed from $0 \mathrm{~V}$ to $0.6 \mathrm{~V}$ at $50 \mathrm{mV} / \mathrm{s}$ in 1 $\mathrm{mM}$ FCA. During these scans, the second interdigitated comb of electrodes were held at $0 \mathrm{~V}$. All electrochemical measurements were recorded versus a saturated calomel electrode (SCE).

\subsection{Electrochemical Analysis of Neonicotinoids}

Imidacloprid and clothianidin were purchased from Sigma-Aldrich and used as received. Acetate buffer was purchased from Sierra Sensors, Germany. Square wave voltammetry (SWV) was performed by sweeping the potential from $-0.2 \mathrm{~V}$ to $-1.4 \mathrm{~V}$ in acetate buffer. All scans were performed using a frequency of $10 \mathrm{~Hz}$, amplitude of $50 \mathrm{mV}$ and a potential step of $4 \mathrm{mV}$. Blank SWV of acetate buffer ( $\mathrm{pH}$ ) were also obtained for the purpose of background subtraction. Imidacloprid and clothianidin stock solutions (in methanol- DI water, 1:1) were prepared at different concentrations, and were added sequentially to $90 \mu \mathrm{L} \mathrm{AB}$ in the cell using a serial addition approach. Five replicate SWV scans were undertaken for each addition. All experiments were performed at room temperature.

\subsection{Electrochemical Reduction of Nitrate}

SWV was also used for the electroanalysis of nitrate. First, copper was deposited onto a platinum electrode to facilitate selective nitrate detection. The deposition was done using chronoamperometry in an electrolyte of copper sulphate with boric acid ( $\mathrm{pH} 2)$. A constant voltage of $-0.3 \mathrm{~V}$ was applied to the working electrode versus the reference electrode for $300 \mathrm{~s}$. The electrochemical studies were done using $0.1 \mathrm{M} \mathrm{Na}_{2} \mathrm{SO}_{4}$ buffer adjusted to $\mathrm{pH} 2$ using $\mathrm{H}_{2} \mathrm{SO}_{4}$. Different nitrate concentration $(1 \mathrm{mM}-$ $100 \mathrm{mM})$ were made using sodium nitrate $\left(\mathrm{NaNO}_{3}\right)$ additions. The SWV was undertaken at a working electrode in the range of -0.4 to $-1 \mathrm{~V}$, with a scan rate of $0.01 \mathrm{~V} \mathrm{~s}^{-1}$ with a frequency of $20 \mathrm{~Hz}$ and modulation amplitude of $0.02 \mathrm{~V}$.

\section{$2.8 \mathrm{pH}$ Control at $\mu$ IDE Arrays}

A series of buffers of differing $\mathrm{pH}$ was used to study the gold oxide reduction reaction. $0.1 \mathrm{M}$ citric acid (Riedel-de Haën, 99.5\% anhydrous) and 0.2 M sodium phosphate dibasic (Merck, 99\% anhydrous) were mixed in appropriate ratios to yield buffers with $\mathrm{pH}$ values of 3.6, 4.6 and 7.6, respectively. $0.2 \mathrm{M}$ sodium phosphate dibasic and $0.2 \mathrm{M}$ sodium phosphate monobasic (Sigma Aldrich, 99\%) were mixed to make a pH 8.6 buffer, while $0.1 \mathrm{M}$ sodium carbonate (Sigma Aldrich, 99\%) and $0.1 \mathrm{M}$ sodium bicarbonate (Sigma Aldrich, 99.5\%) were mixed to yield $\mathrm{pH} 9$ and 10 buffers. Voltammetric analysis was performed in each buffer over the potential range 0 to $1.4 \mathrm{~V}$ (versus $\mathrm{Ag} / \mathrm{AgCl}$ ) at $50 \mathrm{mV} / \mathrm{s}$. Potential range was adjusted to account for $\mathrm{pH}$ variability. The $\mathrm{pH}$ control method was tested in a sample of $1 \mathrm{mM}$ Sodium Bicarbonate in DI water. Generation of acidic conditions was done by biasing the protonator electrode at $1.8 \mathrm{~V}$ vs. $\mathrm{Ag} / \mathrm{AgCl}$, basic conditions were generated by biasing the protonator at $-1.3 \mathrm{~V}$ vs. $\mathrm{Ag} / \mathrm{AgCl}$.

Stock solutions of 200 parts per million (ppm) monochloramine (MCA) were prepared and diluted with the relevant matrix to make MCA working samples. The MCA stock solution was prepared by slowly mixing a 1:1 ratio of sodium hypochlorite $(\mathrm{NaOCl}, 5 \%$ Milton Sterilising Fluid) and 
ammonium chloride $\left(\mathrm{NH}_{4} \mathrm{Cl}\right.$, Sigma Aldrich $\left.>99 \%\right)$. The $\mathrm{NaOCl}$ was prepared by diluting a $5 \%$ bleach solution in DI water and adjusting to $\mathrm{pH} 8.3$ with $1 \mathrm{M} \mathrm{NaOH}$. The $\mathrm{NH}_{4} \mathrm{Cl}$ was dissolved in DI water and adjusted to $\mathrm{pH} 8.3$ using $1 \mathrm{M} \mathrm{HCl}$. The slow mixing ensures that $\mathrm{NH}_{3}$ is in excess, which promoted the formation of MCA. The solution was then let sit for 5 minutes to ensure that the reaction was complete. Electrochemical analysis of MCA solutions via $\mathrm{pH}$ control was undertaken. The starting potential was reduced to $0.95 \mathrm{~V}$ for later work. The protonator electrode was held at $1.75 \mathrm{~V}$. Working samples were made by diluting the MCA stock solution with DI water. In this case, a 5 (ppm) sample was used for analysis.

\subsection{Electrode Functionalisation for Biosensor Application}

$\mathrm{CV}$ was employed for electropolymerisation deposition of o-aminobenzoic acid (o-ABA, $50 \mathrm{mM}$ in $0.5 \mathrm{M} \mathrm{H} 2 \mathrm{SO} 4)$ to create a carboxylic terminated polymer layer at a gold electrode surface. Following polymerisation, the electrodes were carefully rinsed with DI water to remove any remaining monomer solution. A fresh mixture of 1:1 EDC/NHS (75 mg/mL EDC and $11.5 \mathrm{mg} / \mathrm{mL} \mathrm{NHS)}$ was deposited onto a chip for $20 \mathrm{~min}$ to activate the carboxylic acid surface. Working electrodes were coated with capture biomolecules and allowed incubate for 1 hour at $4{ }^{\circ} \mathrm{C}$ to allow covalent attachment to the electrode surface. Following this immobilisation, the electrodes were rinsed well with acetate buffer solution containing $0.1 \%$ Tween-20 (AB-T) and DI water to remove any unbound capture biomolecules. The un-reacted active sites were blocked by immersing in $1 \mathrm{M}$ ethanolamine $\mathrm{HCl}, \mathrm{pH} 8.5$ for 20 mins. Impedance measurement undertaken following this step were considered as the "baseline" for the on-chip sensors. To undertake analysis, as-modified electrodes were exposed to target solutions BVD antibody or virus in buffer by spotting with $2 \mu \mathrm{L}$ aliquots followed by incubation for $10 \mathrm{~min}$ at room temperature. Electrodes were again rinsed thoroughly with HBS-EP buffer and DI water to remove non-specifically bound target biomolecules prior to subsequent electrochemical measurement. All data were fitted using an equivalent circuit using NOVA software and experimental data were background subtracted using the values for the ethanolamine baseline as defined.

\subsection{Detection of BVD Antibodies and Virus}

For antibody detection, electrodes were modified using with BVD Virus-1 Erns antigen as the capture biomolecule. A concentration of $100 \mu \mathrm{g} / \mathrm{mL}$ (acetate buffer, $\mathrm{pH} 4$ ) was prepared, deposited and allowed incubate for 1 hour at $4^{\circ} \mathrm{C}$. BVDAb detection was then investigated in solutions of increasing biological complexity. BVDAb in HBS-EP buffer, prepared using BVD monoclonal antibody (RAE0823 as purchased stock sample) diluted into working solutions of varying dilution (1:10 to 1:1000, respectively) using HBS-EP buffer, (

For virus detection, electrodes were modified using BVD monoclonal antibody, specific to Erns antigen, as the capture biomolecule $(100 \mu \mathrm{g} / \mathrm{mL}$, acetate buffer, $\mathrm{pH} 4)$; incubated for 1 hour at $4{ }^{\circ} \mathrm{C}$. Employing antibodies to detect the Erns protein requires minimal processing as Erns is secreted from infected cells during virus replication at an adequate concentration to be used for testing serum.[34, 35] BVDV in HBS-EP buffer, prepared using target Erns viral antigen (as purchased stock sample) diluted into working solutions of varying dilution (1:10 to 1:1000, respectively) using HBS-EP buffer.

\subsection{Integation with electronics}

A commercially viable means of interfacing to ultra-micro scale electrochemical sensors was developed, as described by Murphy et al.[25] This was achieved by utilising an inexpensive potentiostatic system on chip, the ADuCM350.[36] Utilising a system on chip dramatically reduced the cost of the system as discrete components were not required to realise the potentiostat. A digital to analog controller, the AD5683R was also used to enable an interface to dual electrode electrochemical sensors.[37] Voltammetric tests such as Cyclic, Square Wave and Generator Collector 
voltammetry can be performed by the device. The system can be interfaced to a smartphone through Bluetooth. Test parameters can be easily programmed through a smartphone application and the results can be saved as a text file to the cloud. It is battery powered and of suitable form factor for point of sample electrochemical measurements.

\section{Results}

\subsection{Electrode Array Characterisation}

Electrode arrays were fabricated as described in the experimental section above. Each chip contains 6 gold working electrodes, along with single Pt reference and Au counter electrodes. The devices were characterised using optical microscopy. Figure 1 (a) shows an optical micrograph of the fully fabricated chip device containing the 6 electrically isolated electrode arrays with the Au counter and Pt reference electrodes respectively. Figure 1 (b) shows an optical micrograph of a typical IDE sensor with a $2 \mu \mathrm{m}$ gap between electrode combs. The protonator comb (left hand side) contains 14 electrodes, while the sensor comb (right hand side) has 13 electrodes. Figure 2 (c) shows an optical micrograph of a typical array with four nanowire electrodes $100 \mathrm{~nm}$ wide and separated by $500 \mathrm{~nm}$. The width of the passivation window (central dark rectangle) defined the exposed electrode length at $45 \mu \mathrm{m}$ for both arrays.

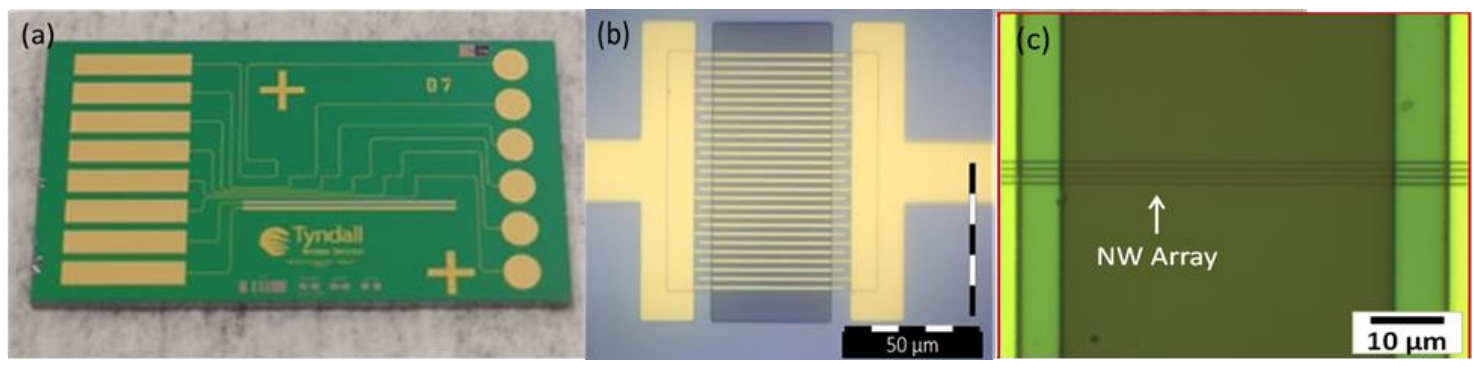

Figure 1: (a) Image of the fully fabricated chip with 6 sensors, counter and reference electrodes. (b)

Higher magnification image of one IDE sensor. (c) Higher magnification image of one nanowire array.

Nanowire electrodes were structurally characterised in detail previously, by Barry et al., using a combination of optical, electron and atomic force microscopy and electrically characterised using two point current voltage measurements.[38] Furthermore, cyclic voltammetry characterisation was performed by applying a potential range of $-0.2 \mathrm{~V}$ to $0.6 \mathrm{~V}$ to the nanowire arrays in $1 \mathrm{mM}$ FCA in 10 $\mathrm{mM}$ PBS, pH 7.4, at $100 \mathrm{mV} \mathrm{s}^{-1}$; see Figure 2 (a). The magnitude of the current ( 2.5 nA) is typical of a nanoelectrode array and exhibits steady-state behaviour, as expected. This confirms that the silicon nitride passivation layer has been removed to expose the gold nanowire array and successfully shields the rest of the chip from unwanted electrochemical reactions. Only chips that exhibit this current behaviour in FCA were used for experiments; chips that demonstrated low or no electrochemical current were discarded and not used for further experiments. Figure 2 (b) shows a typical SWV of $1 \mathrm{mM}$ FCA in $10 \mathrm{mM}$ PBS, pH 7.4 (frequency $10 \mathrm{~Hz}$, amplitude $50 \mathrm{mV}$ and a potential step $4 \mathrm{mV}$ ) displaying a current peak in the voltage range of 0.15 to $0.25 \mathrm{~V}$ vs. the on-chip Pt pseudoreference electrode. This oxidation peak is in agreement with the CV data, and further validated the oxidation of FCA is occurring at the electrodes. 
(a)

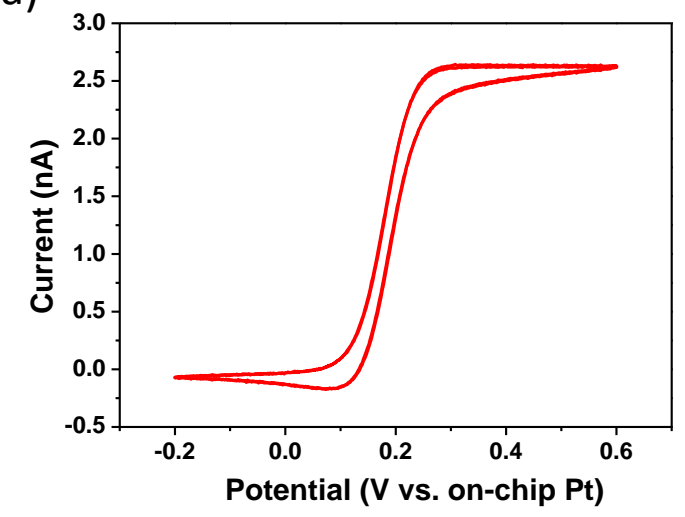

(b)

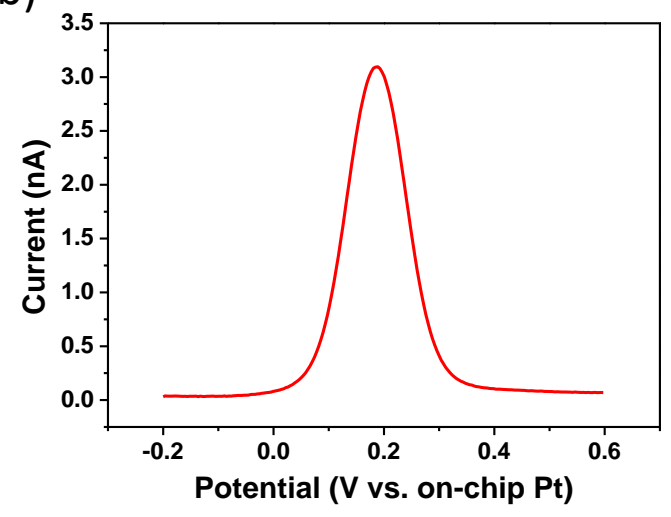

Figure 2: (a) Cyclic voltammogram and (b) Squarewave voltammogram of 1 mM FCA in $10 \mathrm{mM}$ PBS, pH 7.4, at $100 \mathrm{mV} \mathrm{s}-1$ vs. on-chip Pt pseudo-reference electrode; illustrating the steady-state behaviour of a $4 \times 100 \mathrm{~nm}$ nanowire array separated by a distance of $500 \mathrm{~nm}$.

Similarly, the $2 \mu \mathrm{m}$ gap IDE arrays were characterised in FCA, initially with no bias at the collector electrodes. As the arrays consist of micron scale electrodes separated by gaps of the same scale, diffusional overlap was expected. Figure 3 (a) shows the effect that varying the scan rate had on the IDE array. The slower scan rates exhibited a quasi-steady state behaviour, displaying a plateau rather than a peak shape. As the scan rate was increased, the behaviour changed significantly, exhibited diffusion limited peaks were observed rather than plateaus. This is indicative of the arrays behaving like one larger electrode due to radial diffusion overlap, rather than multiple smaller electrodes. Each IDE was then further characterised in generator-collector mode by biasing a collector electrode at a fixed potential and scanning the generator at a varied scan rate. Figure 3 (b) shows the result of biasing the collector electrode at $0 \mathrm{~V}$ while scanning the generator at 10,100 and $1000 \mathrm{mV} / \mathrm{s}$. In generator-collector mode, the oxidised FCA species produced at the generator diffuses across to the collector where it is subsequently reduced. This has two significant benefits. Firstly, there is no diffusional overlap as the collector prevents this from happening, resulting in the array behaving as desired. Secondly, The FCA is redox cycled between the two combs of electrodes amplifying signal response. The scan rate is shown to have very little impact for the generator-collector scans, as each electrode is acting independently.
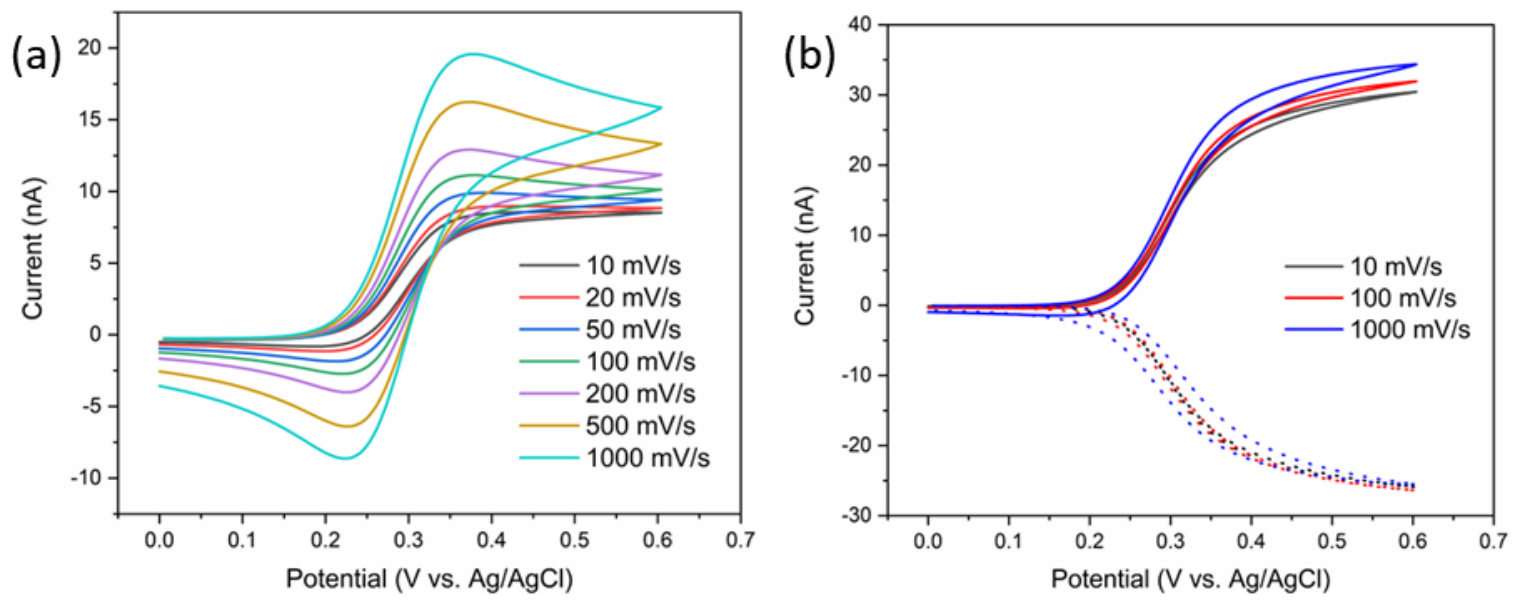

Figure 3: Cyclic voltammograms of $1 \mathrm{mM} \mathrm{FCCOOH}$ in $10 \mathrm{mM}$ PBS, $\mathrm{pH}$ 7.4, at various scans rates with the collector (a) unbiased and (b) biased at $0 \mathrm{~V}$ vs. $\mathrm{Ag} / \mathrm{AgCl}$

\subsection{Neonicotinoid Detection at Nanowire Arrays}

Following electrochemical characterisation, nanowire arrays were applied to the detection of the neonicitinoid pesticides: clothianidin and imidacloprid. The voltametric reduction signals observed for these compounds arise from the reduction of $\mathrm{NO}_{2}$ groups to $\mathrm{NH}_{2}$ groups, via a two- step electro- 
reduction pathway, which is well documented.[39-42] Firstly, a nitro intermediate followed by a hydroxylamine intermediate are formed via a $4 \mathrm{e}^{-} / 4 \mathrm{H}^{+}$electron and proton transfer system. The hydroxylamine group is further reduced to an amine via a $2 \mathrm{e}^{-} / 2 \mathrm{H}^{+}$electron and proton transfer system. Compared to $\mathrm{CV}, \mathrm{SWV}$ is a very sensitive electrochemical method that permits fast scan rates, significantly reduces background noise and as such is suitable for remote electroanalysis. Combining this approach with the sensitivity of nanowire electrodes permits detection in simple acetate buffer thereby obviating the requirement for more complex mixed acid solutions such as Britton-Robinson buffer.[40, 43, 44] It was demonstrated previously that $\mathrm{pH} 4$ to 9 is optimum for imidacloprid determination.[45] On this basis a $\mathrm{pH}$ of 5 was chosen for imidacloprid determination. Figure 4 (a) shows typical SWV following background subtraction for clothianidin in the concentration range of $0.88 \mathrm{nM}-378 \mathrm{nM}(0.22 \mathrm{ng} / \mathrm{mL}-94.57 \mathrm{ng} / \mathrm{mL})$. The reduction peaks at $-1.07 \mathrm{~V}$ and $-1.18 \mathrm{~V}$ represent the two-step reduction of the nitro group of imidacloprid; supporting the reduction mechanism for nitro group reduction. The first reduction is attributed to the four electron transfer of the nitro group to yield the corresponding hydroxylamine derivative. The second reduction peak $\sim-1.18 \mathrm{~V}$ is attributed to the two electron transfer from the hydroxylamine to produce its amine derivative.[46, 47] To demonstrate the suitability of the nanowire arrays as sensors for clothianidin, calibration experiments were undertaken to examine the effects of increasing concentration on the SWV signals using a serial addition approach. Figure 4 (b) shows the calibration plot obtained by plotting the peak height at $\sim-1.07 \mathrm{~V}$ versus log of concentration. Each measurement was undertaken five times to monitor the stability and reproducibility of the electrodes and the error bars represent one standard deviation from the mean value of the five replicates. The measured detection limit for clothianidin was $0.22 \mathrm{ng} / \mathrm{mL}(0.88 \mathrm{nM})$ and a calibration coefficient of $R^{2}=0.984$ shows good linearity with increasing concentration in this concentration range.

(a)

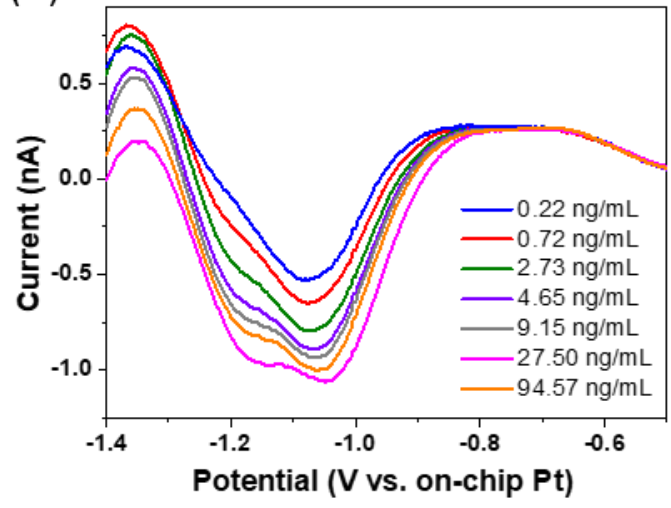

(b)

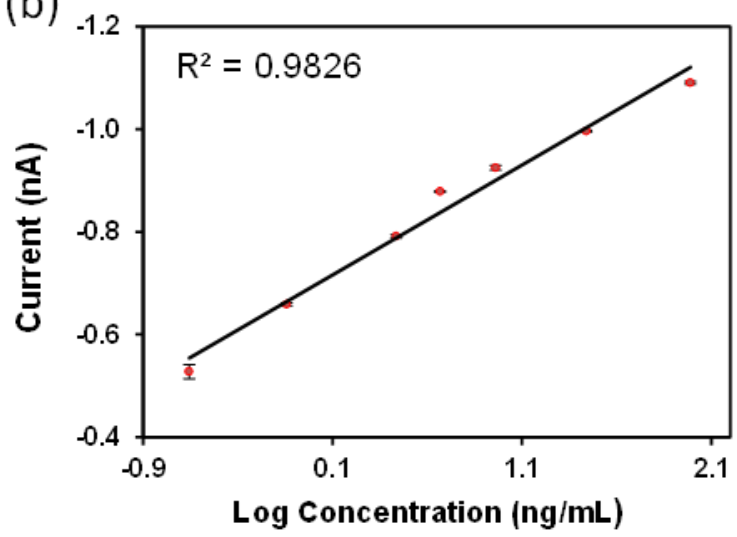

Figure 4: (a) Square wave voltammogram of Clothianidin recorded at different concentrations in acetate buffer (pH 5) versus on-chip Pt pseudo reference electrode. (b) Calibration plot of peak current vs. log concentration of clothianidin solution. Error bars are included in clear data points.

Similarly, Figure 5 (a) shows the SWV of imidacloprid in the concentration range of $8 \mathrm{nM}-4.1$ $\mu \mathrm{M}(2.15 \mathrm{ng} / \mathrm{mL}-1.05 \mu \mathrm{g} / \mathrm{mL})$ following background subtraction. The CV again shows the two reduction peaks representing the nitro-group reduction of imidacloprid with the peaks at $\sim-1.05$ and $-1.2 \mathrm{~V}$ being attributed to the first and second reduction steps, respectively. The quantitative determination of imidacloprid at gold electrodes is based on the semi-log relationship between peak current intensity (nA) and imidacloprid concentration. Figure 5 (b) shows the calibration plot obtained by plotting the peak current at approx. $-1.2 \mathrm{~V}$ versus log of concentration. Again, each measurement was undertaken five times to monitor the stability and reproducibility of the electrodes and the error bars represent one standard deviation from the mean value of the five replicates. The measured limit of detection was $2.14 \mathrm{ng} / \mathrm{mL}(8 \mathrm{nM})$ and a coefficient of $\mathrm{R}^{2}=0.989$ shows good linearity with increasing concentration in this concentration range. This concentration range is lower than the 
lowest legal residue limit of $\sim 10 \mathrm{ng} / \mathrm{mL}$ for food products thus demonstrating the suitability of this technique.[48]
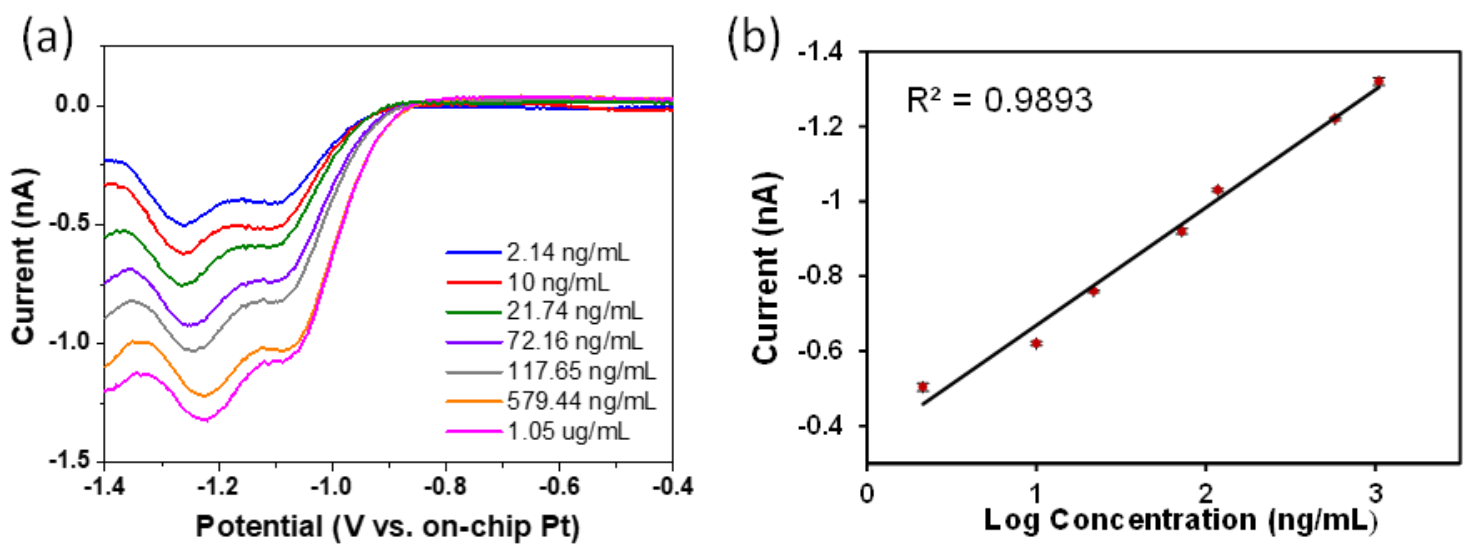

Figure 5: (a) Square wave voltammogram of Imidacloprid recorded at different concentrations in acetate buffer ( $\mathrm{pH}$ 5) versus on-chip Pt pseudo reference electrode. (b) Calibration curve of peak current vs. log concentration of imidacloprid. Error bars are included in clear data points

\subsection{Electrochemical Detection of Nitrates}

An electrochemical deposition process described in the experimental section was used to deposit copper nanostructures on the surface of the platinum microband electrode, and is shown in the inset of figure 6 (a). The reaction and kinetics of the copper nucleation on platinum microelectrodes could be used to explain morphology achieved during the deposition. Longer deposition times resulted in larger copper nanostructures being formed. Since the electrochemical deposition is performed in acidic $\mathrm{pH}$, hydrogen evolution occurs simultaneously with the copper deposition (Eq-1,2).

$$
\begin{gathered}
\mathrm{Cu}^{2+}+2 e^{-} \rightarrow \mathrm{Cu} \\
2 \mathrm{H}^{+}+2 e^{-} \rightarrow \mathrm{H}_{2}
\end{gathered}
$$

As the deposition voltage of $-0.3 \mathrm{~V}$ is applied, a constant stream of $\mathrm{H}_{2}$ is evolved, resulting in $3 \mathrm{D}$ nanoporous copper structures being formed on the surface of the platinum microelectrode.

SWV was used for the electroanalysis of nitrate, the results of which are shown in figure 6 (a). It has been shown that under acidic conditions, nitrate can be reduced to ammonium ions according to the following equation (Eq.3).

$$
\mathrm{NO}_{3}^{-}+8 e^{-}+10 \mathrm{H}^{+} \rightarrow \mathrm{NH}_{4}^{+}+3 \mathrm{H}_{2} \mathrm{O}
$$

To examine the sensor performance a linear calibration plot was obtained as seen in Figure 6 (b). It was obtained by increasing the concentration of $\mathrm{NO}_{3}$ using the standard addition method (i.e. 1, $10,15,25,50100 \mu \mathrm{M})$ resulted in a corresponding increase in current. On-chip reference and the counter electrode of platinum and gold was used for the measurement. The sensitivity of the electrode was at $0.038 \mathrm{~A} / \mu \mathrm{M}$ with $\mathrm{R}^{2}=0.99$. The sensitivity of the microelectrode was found to be enhanced because the deposited copper layer shows a porous structure. The large surface area on microelectrode makes it more effective electrocatalyst in facilitating nitrate reduction than the standard macro electrode. The LOD calculated to be $0.2 \mu \mathrm{M}$ with a range of 1-100 $\mu \mathrm{M}$. 

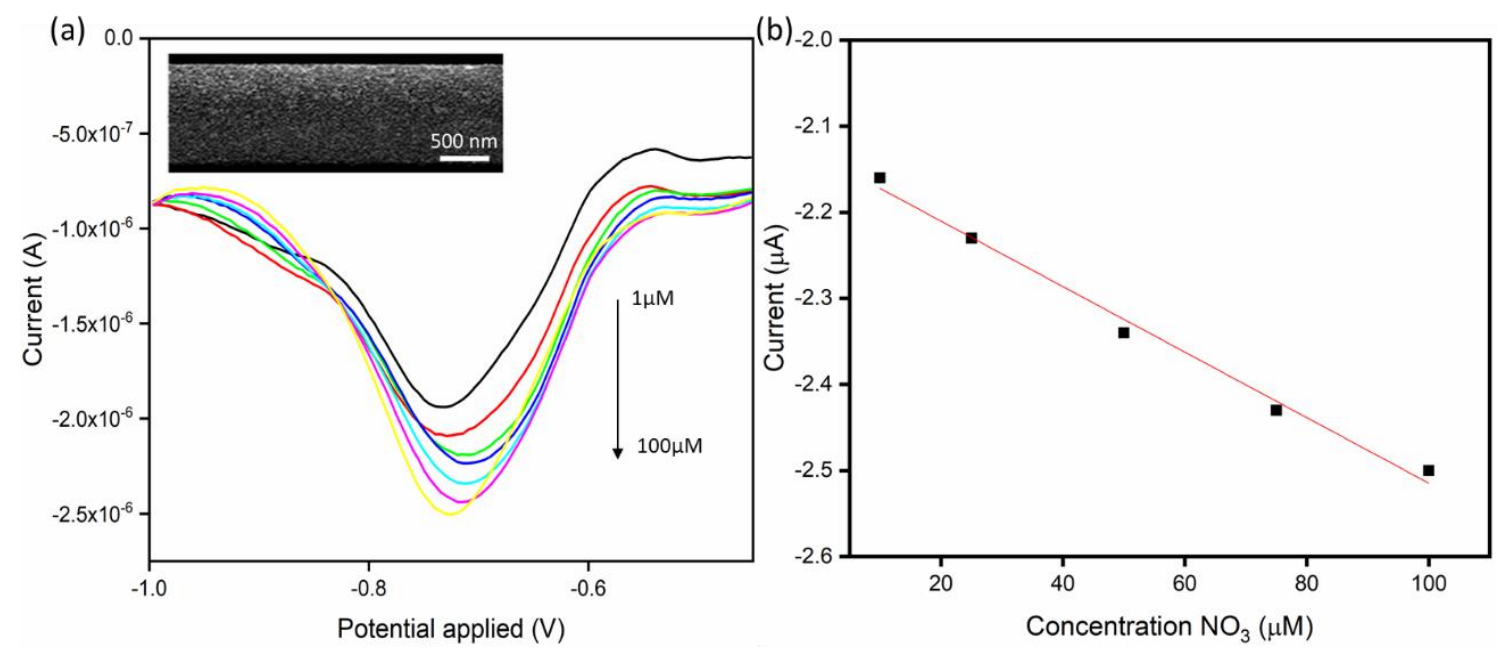

Figure 6: $\mathrm{SWV}$ in increasing concentrations of $\mathrm{NaNO}_{3}$ in $0.1 \mathrm{M} \mathrm{Na}_{2} \mathrm{SO}_{4}$ at $\mathrm{pH} 2$. SWV were performed from -0.4 to $-1 \mathrm{~V}$ at $10 \mathrm{mV} / \mathrm{s}$ with an amplitude of $20 \mathrm{mV}$ and a frequency of $20 \mathrm{~Hz}$. A SEM image of the copper modified electrode is shown in the top inset. The calibration plot is shown in the bottom inset.

\subsection{Electrochemical $p H$ measurement and in-situ $p H$ Control for the conversion of Monochloramine to Dichloramine}

The gold oxide reduction peak was used as a probe for the $\mathrm{pH}$ condition of the electrodes.[49, 50] An oxide was formed on a gold electrode by scanning to a sufficiently positive potential, typically around $1.2 \mathrm{~V}$. The electrode was then swept cathodically to the initial potential and the position of the oxide reduction peak was noted. This procedure was repeated at different $\mathrm{pH}$ values in a series of buffers to establish the linearity of the technique. Figure 7 (a) shows the oxide reduction peaks for the different buffer solutions. In each case, four replicate scans were performed to determine reproducibility. As expected, the oxide peaks shifted to more positive potentials at lower $\mathrm{pH}$ values. The calibration plot, shown in figure 7 (b), indicates a strong linearity with an $\mathrm{R}^{2}=0.999$. The oxide approach to $\mathrm{pH}$ analysis shows a sensitivity of $74 \mathrm{mV} / \mathrm{pH}$, indicated by the slope of the linear fit. The $\mathrm{pH}$ control experiments are shown in figure 7 (c). The initial scan, where no protonator bias was applied, indicates that the sodium bicarbonate sample had an initial $\mathrm{pH}$ of approximately $\mathrm{pH}$. This was established based on the position of the oxide reduction peak at $0.45 \mathrm{~V}$, which correlates to $\mathrm{pH} 8$ using the calibration plot (Figure $7 \mathrm{~b}$ ). With the application of $1.8 \mathrm{~V}$ potential bias at the protonator, local acidic conditions were created. The potential of $1.8 \mathrm{~V}$ is in the oxygen evolution region; thus an excess of protons was produced from the water splitting. Therefore, the sensor electrode was exposed to conditions that were more acidic than the bulk environment, in this case it was approximated to be $\mathrm{pH} 3$, as above. Similarly, more basic conditions could be created by applying a potential of $-1.3 \mathrm{~V}$ at the protonator electrode. With this potential bias, hydrogen gas was produced and an excess of hydroxyl were produced in the vicinity of the sensor electrode. The position of the oxide reduction peak indicated a $\mathrm{pH}$ environment outside of the calibration range, but assuming linearity, was approximated to be around $\mathrm{pH} 11.5$.

The acidic $\mathrm{pH}$ control method was subsequently applied to the conversion of monochloramine to dichloramine. At $\mathrm{pH} 8$ and above, chloramines tend to exist predominantly as monochloramine. As sample $\mathrm{pH}$ becomes more acidic, this monochloramine is converted to dichloramine. This conversion can be monitored electrochemically as dichloramine shows electro-reduction at potentials more anodic than the reduction of monochloramine. Figure 7 (d) shows the result of applying the $\mathrm{pH}$ control method to a $5 \mathrm{ppm}$ sample of monochloramine. Without a protonator bias, no reduction event was observed attributable to the chloramine species. The oxide reduction peak also indicated a $\mathrm{pH}$ environment of approximately $\mathrm{pH}$ 8. By imposing a $1.75 \mathrm{~V}$ bias at the protonator, acidic conditions 
were generated, indicated by the shift in the oxide reduction peak potential. The anodic shift indicated that the local environment was significantly more acidic than the initial conditions. A reduction event with an onset potential of $\sim 0.5 \mathrm{~V}$ was also observed, which was attributed to the reduction of dichloramine, confirming the conversion of monochloramine to the new species. There were two major advantages to applying this technique to the detection of monochloramine. The first was that variability of $\mathrm{pH}$ was eliminated. In real water samples, $\mathrm{pH}$ conditions can vary dramatically as a result of numerous environmental factors. As such, this introduces complications, particularly if the species is $\mathrm{pH}$ sensitive. The second advantage was that the conversion of monochloramine to dichloramine eliminated oxygen as an interfering species. The reduction potential of monochloramine overlaps with the reduction of dissolved oxygen, leading to convoluted signals. Dissolved oxygen is common at various concentrations in water, therefore it cannot be easily background subtracted. The reduction of dichloramine however was found to be free of oxygen interference, thus simplifying its quantification.
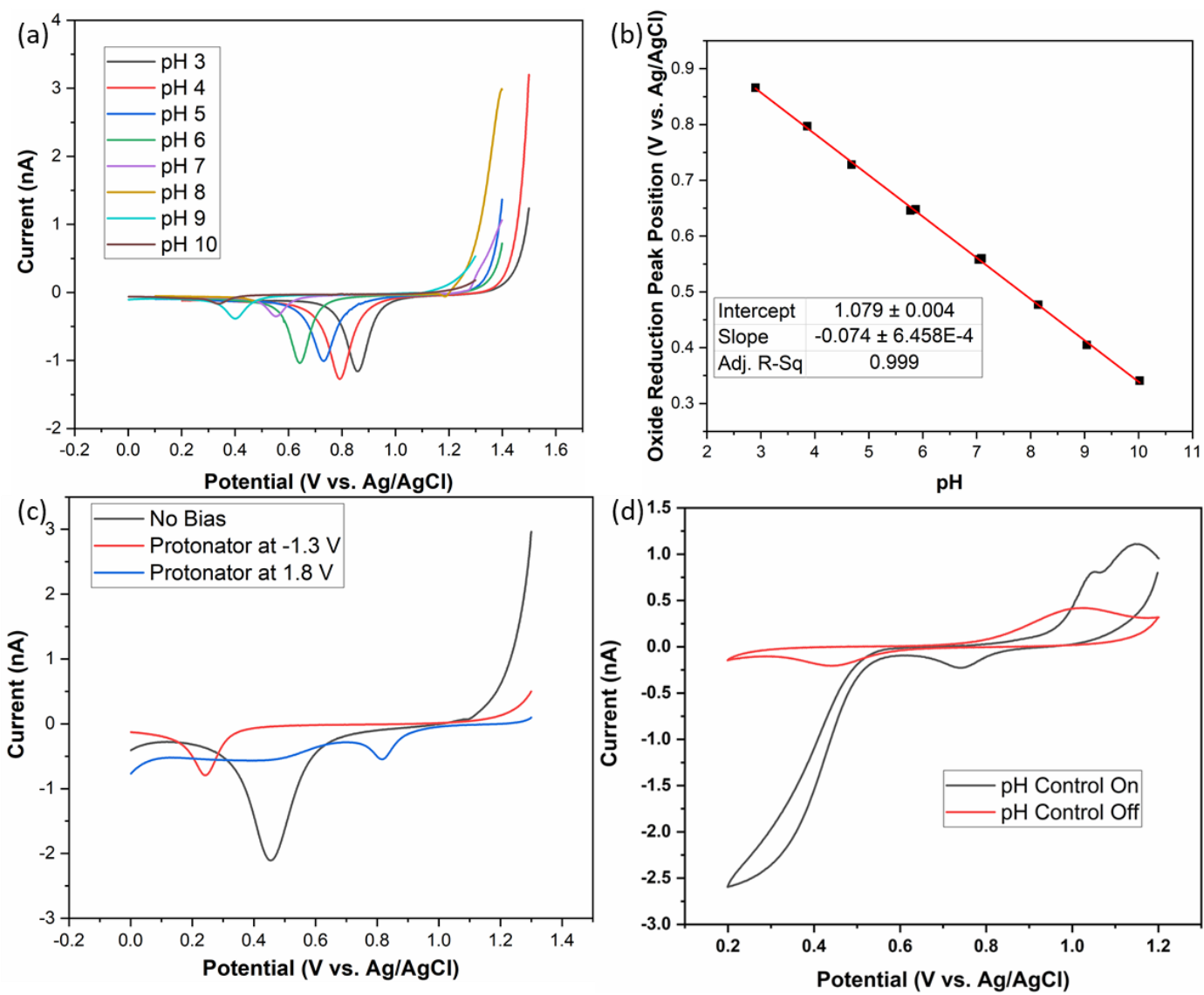

Figure 7: (a) LSV's in various pH buffers from $1.4 \mathrm{~V}$ to $0 \mathrm{~V}$ at $50 \mathrm{mV} / \mathrm{s}$. (b) Calibration of the oxide reduction peak potential vs $\mathrm{pH}$. (c) LSV's of $1 \mathrm{mM}$ Sodium Bicarbonate in DI water from $1.3 \mathrm{~V}$ to $0 \mathrm{~V}$ at $50 \mathrm{mV} / \mathrm{s}$ with various biases applied to the protonator electrode. (d) CV's, from $1.2 \mathrm{~V}$ to $0.2 \mathrm{~V}$ at $50 \mathrm{mV} / \mathrm{s}$, in a 5 ppm sample of monochloramine with and without a potential bias of $1.75 \mathrm{~V}$ at the protonator electrode.

\subsection{BVD Antibody Detection:}

Concerning BVD antibody detection, Figure 8 (a) shows the nyquist diagrams, in presence of $1 \mathrm{mM}$ FCA, measured an electrode surface following modification and exposure to different concentration of target antibody. An increase in the semi-circle diameter, i.e., charge transfer resistance (Rct) and the global capacitance was observed with increasing antibody concentration. This suggests that the antibodies bound to the immobilised Erns antigen, blocking the electrode surface and subsequently restricting electron transfer, i.e. a charge transfer resistance increases with 
increasing concentration of antibody was observed. A modified equivalent circuit, to account for the additional electrode bio-layers, was used to fit the results. This circuit is almost identical to a Randles fit except that an additional resistive and capacitive elements have been added. R1 and R2 both represent the charge transfer resistance, while $\mathrm{C} 1$ and $\mathrm{C} 2$ represent the double layer and coating capacitances respectively. All the capacitances shown in the equivalent electrical circuit are mathematically modelled using a constant phase element (CPE) in NOVA software; and represent all the frequency dependent electrochemical phenomena.

Figure 8 (b) shows that a semi-log linear relationship exists between the charge transfer resistance across the wire, and different dilutions of the stock antibody solution enabling quantitative detection of the antibody. The error bars represent $n=3$ replicates.
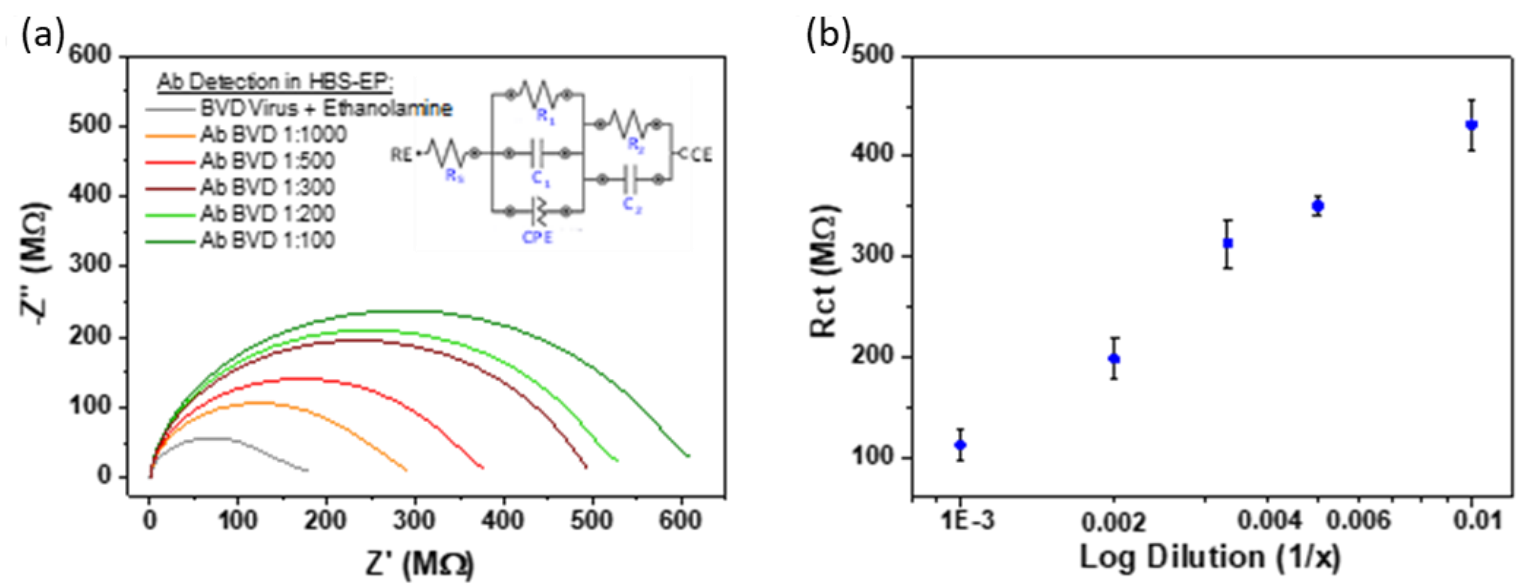

Figure 8: (a) Nyquist plots obtained of o-ABA modified gold nanoband electrode with: BVDV (100 $\mu \mathrm{g} / \mathrm{mL}$ ) modification, ethanolamine blocking and binding of BVDAb in HBS-EP buffer; recorded in $10 \mathrm{mM}$ PBS containing 1 mM FCA. (b) Semi-log relationship of the charge transfer resistance versus antibody dilution (error bars represent $\mathrm{n}=3$ replicates) background subtracted using ethanolamine baseline.

\subsection{BVD Virus Detection:}

Figure 9 (a) shows the nyquist diagrams, in presence of $1 \mathrm{mM}$ FCA, measured an electrode surface following modification and exposure to different concentration of viral protein in HBS-EP buffer ranging from $1 \mathrm{ng} / \mathrm{mL}$ to $10 \mu \mathrm{g} / \mathrm{mL}$. A corresponding increase in measured Rct ( 200M $\Omega$ to $\sim 425$ $\mathrm{M} \Omega$ ) was observed. This increase can be attributed to the virus binding as it acts as kinetic barrier for electron transfer. These results also suggest that the antibody specificity/functionality is not hindered by its covalent attachment to an electrode. Figure 9 (b) shows the semi-log linear relationship between the Rct sensor response and virus concentration thereby suggesting quantitative viral detection is possible with high sensitivity and a large dynamic range $(1 \mathrm{ng} / \mathrm{mL}$ to $10 \mu \mathrm{g} / \mathrm{mL}$ ). Error bars represent $\mathrm{n}=3$ replicates. These results show that the sensor platform is suitable for detection of pathogens and expressed antibodies at physiological concentrations 
(a)

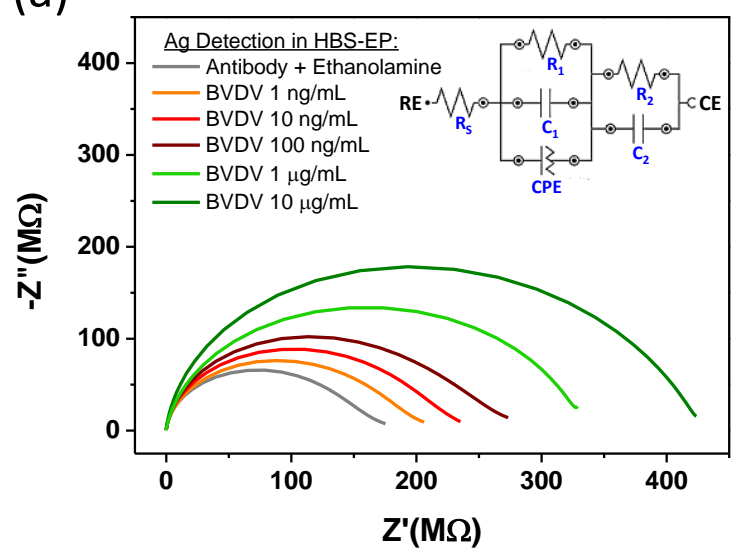

(b)

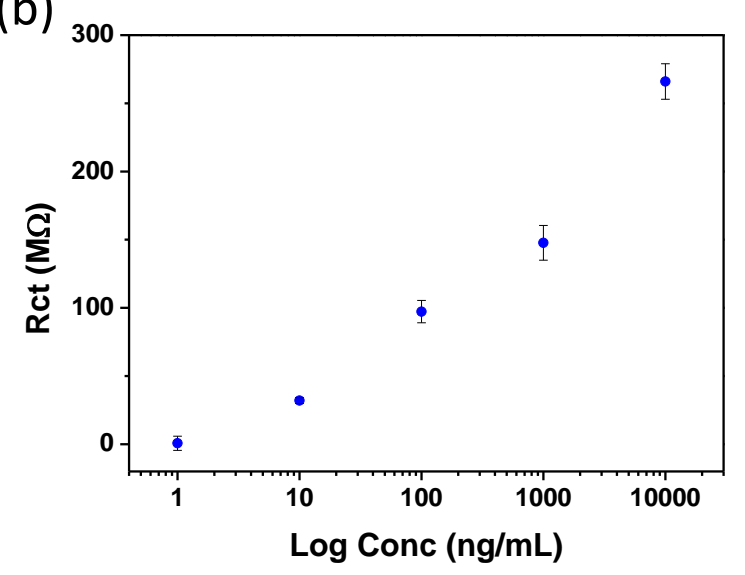

Figure 9: (a) Nyquist plots of 1mM FcCOOH showing quantitative detection of recombinant BVDV1 Erns protein in HBS-EP buffer. (b) Semi-log relationship of the charge transfer resistance versus virus concentration (error bars represent $\mathrm{n}=3$ replicates) background subtracted using ethanolamine baseline.

\subsection{System integration}

A bespoke potentiostat system was developed, using a commercial potientiostat integrated circuit chip, that was capable of controlling the sensor platform, reading the electrochemical response and displaying these results via a smartphone app as shown in figure 10. The system was designed to perform cyclic voltammetry and square wave voltammetry with a 2 volt window, from $-1 \mathrm{~V}$ to +1 $\mathrm{V}$ and also operates in bi-potientiostat mode. The system was benchmarked against a laboratory potentiostat, the PGSTAT302N to show that it is fit for purpose for ultra micro and nano scale electrochemical sensors,.
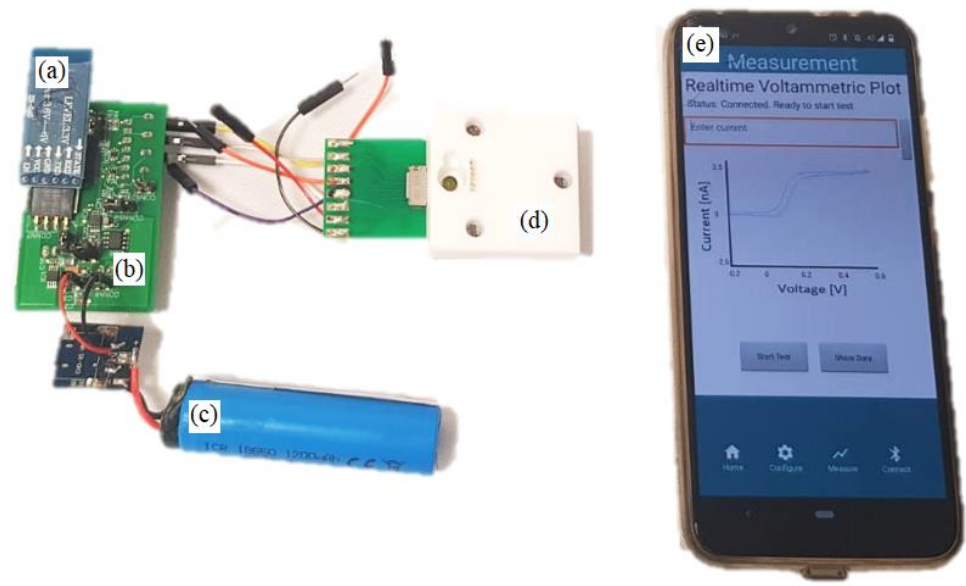

Figure 10 Developed system interfacing to electrochemical sensor with (a) Bluetooth module, (b) developed system printed circuit board, (c) Lithium Ion battery connected to charge protection circuit, (d) electrochemical sensor holder and (e) Smartphone with using developed application.

A cyclic voltammogram was performed using FCA on both systems. As seen from figure 11 the cyclic voltammograms of the two potentiostats are in close alignment. A reduced steady-state current of the developed systems' voltammogram was expected as it was the second measurement taken in the calibration. It's $€ 90.30$ bill of materials price means that the system is a cost effective alternative to portable potentiostats. Similarly, as the data is displayed by means of the smartphone app, no additional interface devices are required to achieve an analytical response. 


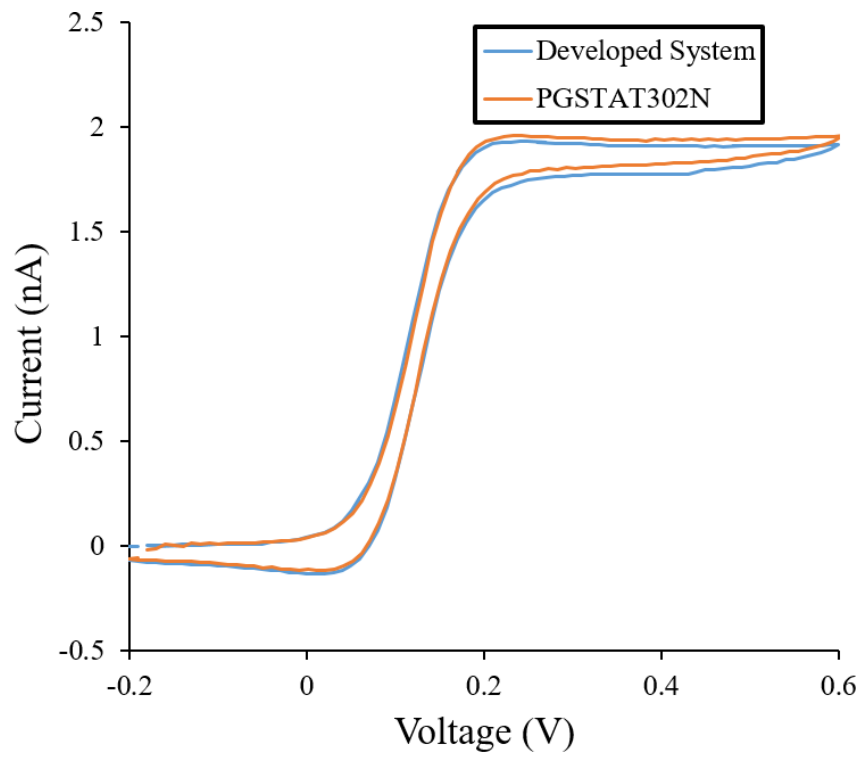

Figure 11: Cyclic Voltammogram swept at 200mV/s using 1mM FCA using both the developed system and the PGSTAT302N.

\section{Conclusion}

In this work, we have shown the versatility of the electrochemical sensor platform by demonstrating a wide range of applications from chemical sensing to biological sensing along with system integration. With the advancement of electrode modification techniques, along with tailored electrochemical analysis, these devices can address many of the sensing requirements associated with the emerging agricultural 4.0 industry. With these devices, the detection of pesticides, fertilisers and infectious diseases was possible on extremely short timescales. These devices can be tailored to be free of matrix interference effects by mitigating $\mathrm{pH}$ variability. This particular technique can promote the detection of a species of interest, or alternatively mask detection of an interfering species. Finally, we have shown a portable electrochemical reader system, capable of performing the desired analysis on farm. The significance of this is that the turnaround time between getting an analytical result and treating the issue is at an absolute minimum, as the two events can be completed in a matter of minutes.

Author Contributions: I.S: Investigation, writing - original draft preparation, formal analysis; T.N: investigation, formal analysis; N.C: investigation, formal analysis; K.K: investigation; investigation, software development, hardware development; R.S:Blood samapling and funding aquisition; E.K: Co supervision I. O'C: Supervision, project administration, funding acquisition; A.O'R: conceptualization, supervision, project management, funding acquisition, writing - review and editing.

All authors have read and agreed to the published version of the manuscript.

Funding: This publication has emanated in part from research supported by a research grant from Science Foundation Ireland and the Department of Agriculture, Food and Marine on behalf of the Government of Ireland under the Grant 16/RC/3835 (VistaMilk), and supported from research conducted with the financial support of Science Foundation Ireland (SFI) and is co-funded under the European Regional Development Fund under Grant Number 13/RC/2077 (Connect), and H2020 project Grant number 825325 (Sarmenti).

Acknowledgments: We would like to thank the fabrication facility at Tyndall National Institute for their role in the production of the devices used in this research.

Conflicts of Interest: The authors declare no conflict of interest.

\section{References}


1. World must sustainably produce 70 per cent more food by mid-century. 2013 [cited 2021 19/02/2021]; Available from: https://news.un.org/en/story/2013/12/456912.

2. De Clercq, M., A. Vats, and A. Biel, Agriculture 4.0: The future of farming technology. Proceedings of the World Government Summit, Dubai, UAE, 2018: p. 11-13.

3. A European Green Deal. [cited 2021 19/02/2021]; Available from: https://ec.europa.eu/info/strategy/priorities-2019-2024/european-green-deal en.

4. Tanaka, A., et al. Wireless self-powered plant health-monitoring sensor system. in SENSORS, 2012 IEEE. 2012.

5. Liew, O.W., et al., Signature Optical Cues: Emerging Technologies for Monitoring Plant Health. Sensors, 2008. 8(5): p. 3205-3239.

6. Helwatkar, A., D. Riordan, and J. Walsh, Sensor Technology For Animal Health Monitoring. International Journal on Smart Sensing \& Intelligent Systems, 2014. 7(5).

7. Ferrer, I., E.M. Thurman, and A.R. Fernández-Alba, Quantitation and accurate mass analysis of pesticides in vegetables by LC/TOF-MS. Analytical Chemistry, 2005. 77(9): p. 2818-2825.

8. Medina-Pastor, P. and G. Triacchini, The 2018 European Union report on pesticide residues in food. EFSA Journal, 2020. 18(4).

9. Tajick, M. and B. Shohreh, Detection of antibiotics residue in chicken meat using TLC. International journal of poultry science, 2006. 5(7): p. 611-612.

10. Herrick, J.E., Soil quality: an indicator of sustainable land management? Applied soil ecology, 2000. 15(1): p. 75-83.

11. Bloem, J., et al., Monitoring and evaluating soil quality. Microbiological methods for assessing soil quality, 2005: p. 23-49.

12. Imran, S., et al., Online Drinking Water Quality Monitoring: Review on Available and Emerging Technologies AU - Banna, Muinul H. Critical Reviews in Environmental Science and Technology, 2014. 44(12): p. 13701421.

13. Association, A.P.H., Standard methods for the examination of water and wastewater. APHA, 16th. Ed., Washington: p. 309 - 315.

14. Lovera, P., et al., Low-cost silver capped polystyrene nanotube arrays as super-hydrophobic substrates for SERS applications. Nanotechnology, 2014. 25(17): p. 175502.

15. Hossain, M.N., et al., High aspect ratio nano-fabrication of photonic crystal structures on glass wafers using chrome as hard mask. Nanotechnology, 2014. 25(35): p. 355301.

16. Roper, J.M., J.F. Garcia, and H. Tsutsui, Emerging Technologies for Monitoring Plant Health in Vivo. ACS Omega, 2021.

17. Agüera, A., et al., Evaluation of photocatalytic degradation of imidacloprid in industrial water by GC-MS and LC-MS. Analusis, 1998. 26(7): p. 245-250.

18. Obana, H., et al., Determination of acetamiprid, imidacloprid, and nitenpyram residues in vegetables and fruits by high-performance liquid chromatography with diode-array detection. Journal of agricultural and food chemistry, 2002. 50(16): p. 4464-4467.

19. Hierold, C., et al., Nano electromechanical sensors based on carbon nanotubes. Sensors and Actuators A: Physical, 2007. 136(1): p. 51-61.

20. Zhao, S., et al., Recent advancements in flexible and stretchable electrodes for electromechanical sensors: strategies, materials, and features. ACS applied materials \& interfaces, 2017. 9(14): p. 12147-12164.

21. McCreery, R.L., Advanced Carbon Electrode Materials for Molecular Electrochemistry. Chemical Reviews, 2008. 108(7): p. 2646-2687. 
22. Gilmartin, M.A.T. and J.P. Hart, Sensing with chemically and biologically modified carbon electrodes. A review. Analyst, 1995. 120(4): p. 1029-1045.

23. Terse-Thakoor, T., et al., Graphene nanogap electrodes in electrical biosensing. Biosensors and Bioelectronics, 2019. 126: p. 838-844.

24. Lee, G.Y., et al., Chronoamperometry-Based Redox Cycling for Application to Immunoassays. ACS Sens, 2018. 3(1): p. 106-112.

25. Murphy, A., et al., Portable Data Acquisition System for Nano and Ultra-Micro Scale Electrochemical Sensors. IEEE Sensors Journal, 2020: p. 1-1.

26. Arrigan, D.W.M., Nanoelectrodes, nanoelectrode arrays and their applications. Analyst, 2004. 129(12): p. 1157-1165.

27. Fan, Y., C. Han, and B. Zhang, Recent advances in the development and application of nanoelectrodes. Analyst, 2016. 141(19): p. 5474-5487.

28. Molina, A., et al., Voltammetry of Electrochemically Reversible Systems at Electrodes of Any Geometry: A General, Explicit Analytical Characterization. The Journal of Physical Chemistry C, 2011. 115(10): p. 40544062.

29. Partel, S., et al., Lift-Off Free Fabrication Approach for Periodic Structures with Tunable Nano Gaps for Interdigitated Electrode Arrays. ACS Nano, 2016. 10(1): p. 1086-92.

30. Partel, S., et al., Novel fabrication process for sub-micron interdigitated electrode arrays for highly sensitive electrochemical detection. Sensors and Actuators B: Chemical, 2014. 205: p. 193-198.

31. Lanyon, Y. and D. Arrigan, Recessed nanoband electrodes fabricated by focused ion beam milling. Sensors and Actuators B: Chemical, 2007. 121(1): p. 341-347.

32. Dawson, K., et al., Fully integrated on-chip nano-electrochemical devices for electroanalytical applications. Electrochimica Acta, 2014. 115: p. 239-246.

33. Dawson, K., et al., Electroanalysis at discrete arrays of gold nanowire electrodes. Electrochimica Acta, 2013. 101: p. 169-176.

34. Kuhne, S., et al., Detection of bovine viral diarrhoea virus infected cattle--testing tissue samples derived from ear tagging using an Erns capture ELISA. J Vet Med B Infect Dis Vet Public Health, 2005. 52(6): p. 272-7.

35. Aberle, D., et al., Structure of the Membrane Anchor of Pestivirus Glycoprotein Erns, a Long Tilted Amphipathic Helix. PLOS Pathogens, 2014. 10(2): p. e1003973.

36. Devices, A., 16-bit precision low power meter on a chip with cortex-M3 and connectivity. Analog Devices, ADuCM350 datasheet, 2014. 2017.

37. Devices, A., Tiny 16-/14-/12-Bit SPI nanoDAC+, with+2 (16-Bit) LSB INL and 2 ppm/C Reference. AD5683R datasheet," Dec, 2013.

38. Barry, S., et al., Highly sensitive detection of nitroaromatic explosives at discrete nanowire arrays. Faraday Discuss, 2013. 164: p. 283-93.

39. Guzsvány, V., et al., Rapid Differential Pulse Polarographic Determination of Thiamethoxam in Commercial Formulations and some Real Samples. Microchimica Acta, 2006. 154(3): p. 321-328.

40. Kumaravel, A. and M. Chandrasekaran, Electrochemical determination of imidacloprid using nanosilver Nafion ${ }^{\circledR} /$ nanoTiO2 Nafion ${ }^{\circledR}$ composite modified glassy carbon electrode. Sensors and Actuators B: Chemical, 2011. 158(1): p. 319-326.

41. Guziejewski, D., S. Skrzypek, and W. Ciesielski, Application of Catalytic Hydrogen Evolution in the Presence of Neonicotinoid Insecticide Clothianidin. Food Analytical Methods, 2012. 5(3): p. 373-380. 
42. Putek, M., et al., Renewable Silver-Amalgam Film Electrode for Rapid Square-Wave Voltammetric Determination of Thiamethoxam Insecticide in Selected Samples. Electroanalysis, 2012. 24(12): p. 2258-2266.

43. Zs., et al. Carbon Paste Electrodes for the Analysis of Some Agricultural Pollutants and Trace Metals. 2011.

44. Brycht, M., et al. Renewable Silver-Amalgam Film Electrode for Direct Cathodic SWV Determination of Clothianidin, Nitenpyram and Thiacloprid Neonicotinoid Insecticides Reducible in a Fairly Negative Potential Range. 2012.

45. Bjelica, L.J. and S.N. krÈsz, Voltammetric determination of imidacloprid and thiamethoxam. Journal of the Serbian Chemical Society, 2005. 70(5): p. 735-743.

46. Guiberteau, A., et al., Study and determination of the pesticide Imidacloprid by square wave adsorptive stripping voltammetry. Talanta, 2001. 53(5): p. 943-9.

47. Navalón, A., et al., Differential-pulse polarographic determination of the insecticide imidacloprid in commercial formulations. Microchimica Acta, 1999. 130(4): p. 261-265.

48. Authority, E.F.S., The 2011 European Union report on pesticide residues in food. EFSA Journal, 2014. 12(5): p. 3694.

49. Seymour, I., et al., Electrochemical detection of free-chlorine in Water samples facilitated by in-situ pH control using interdigitated microelectrodes. Sensors and Actuators B: Chemical, 2020. 325: p. 128774.

50. Wasiewska, L.A., et al., Reagent free electrochemical-based detection of silver ions at interdigitated microelectrodes using in-situ pH control. Sensors and Actuators B: Chemical, 2021. 333: p. 129531. 